\title{
Foreword
}

\section{Nursing in the Pediatric Intensive Care Unit}

\author{
Andrea M. Kline-Tilford ${ }^{1}$ Lauren Sorce ${ }^{2}$ \\ 1 Department of Cardiovascular Surgery, Children's Hospital of \\ Michigan, Detroit, Michigan, United States \\ 2 Division of Pediatric Critical Care, Ann and Robert H. Lurie Children's \\ Hospital of Chicago, Chicago, Illinois, United States
}

J Pediatr Intensive Care 2015;4:55.

This special edition of the Journal of Pediatric Intensive Care includes an array of topics commonly encountered in pediatric intensive care units around the world. Hospital-associated infections, artificial airway suctioning, sedation, and multidrug-resistant organisms are just a few of the eight topics in this special edition. This edition of the journal differs from prior editions in that each evidenced-based paper was selected for its timeliness and applicability to pediatric nursing. Contributors to this issue represent several members of the interprofessional team, and highlights contributions from nursing professionals.

Hospital performance quality care measures, including patient outcomes, can significantly impact reimbursement and patient satisfaction. Given the impact of nursing on the care of critically ill children, integration of evidence-based practice (EBP) at the bedside is essential to optimize patient outcomes. Each member of the health care team, including nurses, can contribute to providing the best care and outcomes for patients and families not only by performing research, but also through knowledge of the latest evidence and facilitating changes in clinical practice based on the evidence. A commitment to EBP is essential from hospital leaders, providers, and bedside caregivers. Providing education about EBP, reviewing methods for performing literature reviews, and implementing an EBP framework are tools to successfully adopt EBP. ${ }^{1}$ Nurses and other members of the interprofessional team are charged with discussing and integrating the latest evidence on daily patient rounds.
Strategies for sustaining EBP models can include providing all health care professionals with continuous access to clinical web-based information (e.g., EBP databases, professional organization Web sites), establishing unit- or hospital-based EBP councils or committees, providing guidance on EBP initiatives through the presence of research nurse scientists, developing unit/department-based journal clubs, and incorporating EBP on performance appraisals. ${ }^{1-4}$ All members of the health care team are essential in the commitment to EBP.

We think that this compilation of papers provides a sampling of topics that readers will find appealing and applicable to clinical practice. Each topic in this special issue was examined using an evidence-based approach. We encourage you to share this evidence with your colleagues and challenge you to make a difference in your clinical practice based on the evidence contained. Thank you and enjoy.

\section{References}

1 Pitkänen A, Alanen S, Rantanen A, Kaunonen M, Aalto P. Enhancing nurses' participation in implementing evidence-based practice. J Nurses Prof Dev 2015;31(2):E1-E5

2 Gawlinski A, Rutledge D. Selecting a model for evidence-based practice changes: a practical approach. AACN Adv Crit Care 2008; 19(3):291-300

3 Oman KS, Duran C, Fink R. Evidence-based policy and procedures: an algorithm for success. J Nurs Adm 2008;38(1):47-51

4 Schulman CS. Strategies for starting a successful evidence-based practice program. AACN Adv Crit Care 2008;19(3):301-311, quiz 312-313
Address for correspondence Andrea M. Kline-Tilford, MS, CPNPAC/PC, FCCM, Department of Cardiovascular Surgery, Children's Hospital of Michigan, Detroit, Michigan, United States (e-mail: aklinetilford@gmail. com).
Issue Theme Nursing in the

Pediatric Intensive Care Unit; Guest Editors: Andrea M. KlineTilford, MS, CPNP-AC/PC, FCCM, and Lauren Sorce, MSN, RN, CPNPAC/PC, CCRN, FCCM
Copyright $\odot 2015$ by Georg Thieme Verlag KG, Stuttgart · New York
DOI http://dx.doi.org/ $10.1055 / \mathrm{s}-0035-1556746$. ISSN 2146-4618. 